breast development which presents as a unilateral "lump" behind the nipple. I have seen this so often that I am amazed it is not more universally recognised.

ROBIN BURKITT Ashford Hospital, Ashford. Mddx

SIR,-Your leading article on this subject (4 February, p 260) reads more like the advice column of a woman's weekly than the editorial of a learned medical journal.

The suggestion that a delay of two months before biopsy of a breast lump in a young girl is not a safe policy is difficult to substantiate. The evidence in breast carcinoma is that it has a very long subclinical natural history. Additionally, treatment has little effect on survival, particularly in the rapidly growing cases such as that referred to by Teasdale and Baum.

I fear your article will bring a further batch of young women to surgical clinics with fibroadenosis. Many have been made neurotic by the suggestion of magazines, friends, and doctors that biopsy is "advisable." Not only is it unhelpful in this condition, but there is the expense to the Health Service, the risk of a general anaesthetic, and the resultant scarring to consider. If there is an unequivocal lump thought to be a fibroadenoma most surgeons excise this in any case, as they seldom disappear and usually grow larger.

In conclusion, surgery should not be used "to give them and their parents peace of mind" but only to alleviate disease. Anecdotal evidence of solitary case reports must not be used to support a universal policy the net effect of which may be harmful.

Bury General Hospital,

DAVID BAUMBER

Bury General
Bury, Lancs

${ }^{1}$ Teasdale, C, and Baum, M, Lancet, 1976, 2, 627.

\section{Bromocriptine-induced mania?}

SIR,-Bromocriptine is probably a long-acting dopamine receptor stimulant ${ }^{12}$ which has central stimulant effects. ${ }^{3}$ It has been used to suppress lactation and to treat amenorrhoea and infertility. It reduces prolactin levels and in amenorrhoea enhances either the secretion or the activity of follicle-stimulating hormone and luteinising hormone. It has recently been suggested that by lowering plasma prolactin bromocriptine should prevent mania. ${ }^{4}$

We would like to report a case in which it seems that bromocriptine induced mania. Our patient was 27 years old and two weeks post partum. She had received bromocriptine twice daily for seven days and then became excited. One day later she was compulsorily admitted. She had flight of ideas and religious and grandiose delusions. She had a sense of mission, motor hyperactivity, and gross elation. No previous psychiatric history was elicited. Bromocriptine was discontinued and haloperidol $10 \mathrm{mg}$ thrice daily prescribed for three days. Within $36 \mathrm{~h}$ the signs disappeared. She was discharged on the third day without medication and has remained well for three months. We suspect that bromocriptine was responsible for her psychosis.

Our observations therefore lead us to view the use of bromocriptine for mania with caution. 5 Our patient, however, may have simply developed an acute puerperal psychosis, but this report seems justified if only to encourage others to comment from their own experience. Certainly bromocriptine is widely used to our knowledge in Sheffield and Doncaster without regularly causing such a syndrome.

D N VLISSIDES DAVID GILI J Castelow

Psychiatric Unit and Drug
Information Unit,

Doncaster Royal Infirmary,
Doncaster, S Yorks

${ }^{1}$ Fluckiger, E, Proceedings of a Symposium held at the Royal College of Physicians of London, 16 May 1976.

${ }^{2}$ Corrodi, H, et al, fournal of Pharmacy and Pharmacology, 1973, 25, 409.

${ }^{3}$ Johnson, A M, Loew, D M, and Vigouret, J M, British .7ournal of Pharmacology, 1976, 56, 59.
Dorr, L, and Sathananthan, K, British Medical fournal, 1976, 2, 1343 Journal, 1976, 2, 1343.
Lees, A J, British fournal of Hospital Medicine, 1977,
18, 336.

\section{Treatment of normal-weight diabetics}

SIR,-Drs D A Pyke and P J Watkins (21 January, p 172), commenting on our paper (17 December, p 1576), recommend that metformin should be given in doses no greater than 1500 or $1700 \mathrm{mg}$ daily, although no data are cited to support this. Moreover, one of them, as recently as late 1977 , had given the upper dosage of metformin as $3000 \mathrm{mg}$ in an authoritative journal for prescribers. ${ }^{1}$ Using the upper limit of $2.0 \mathrm{~g}$ recommended by the British National Formulary 1976-78 $70 \%$ of our satisfactorily controlled patients were receiving this or a smaller dosage. A lower dose, however, does not necessarily decrease the risk of the rarely encountered metforminassociated lactic acidosis, as was seen in three of the six cases reported by Assan et $a l^{2}$ in which the daily dose was $1.6 \mathrm{~g}$. We therefore feel that in the proper use of metformin, rather than undue preoccupation with dosage, the emphasis should be more on constant vigilance for conditions predisposing to lactic acidosis, especially renal impairment and situations liable to produce hypoxia.

In reply to Dr M C Bateson (21 January, p 172) the "standard weights" referred to in our article were those of the Metropolitan Life Insurance Company, 1959.

B F CLARKE IAN W CAMPBELL

Diabetic and Dietetic Department, Royal Infirmary, Edinburgh 1 Watkins, P J, Prescribers' fournal, 1977, 17, 76
' Assan, R, et al, Diabetologia, 1977, 13, 211.

\section{Choosing an antidepressant}

SIR,-In your leading article on this subject (21 January, p 128) there is one important factor you did not mention which could influence any decision of choice. The metabolism of tricyclic antidepressants is by their conversion in the liver, a small amount being excreted unchanged in the urine. Tricyclics may produce an obstructive type of jaundice similar to that with phenylthiazine, and there is a risk of enhanced toxicity due to slower metabolism following infective hepatitis. Thus tricyclics are contraindicated in patients with impaired liver function. Quadracyclic antidepressants are also metabolised in the liver and should be given with extreme caution in any such patients.
The alternatives are: (1) to select a tricyclic antidepressant which is metabolised directly to an inactive metabolite-for example, nortriptyline rather than amitriptyline-and keep the initial dosage low; or (2) to use the bicyclic antidepressant viloxazine, which is not metabolised in the liver, $98 \%$ being excreted in the urine, and would appear to be the drug of first choice in the treatment of depression in patients with impaired liver function.

G W LEWIS

District Pharmacy,

North Lonsdale Hospital,
Barrow-in-Furness, Cumbria

SIR,-Your helpful review of antidepressant therapy (21 January, p 128) failed to mention a common serious side effect with any tricyclic antidepressant-acute confusion. Some would consider this to be a greater problem in terms of frequency and disability than the cardiotoxic effects of these drugs.

Colin Powell

Department of Medicine

(Geriatric Medicine)

Penicillamine: its place in rheumatology

SIR,-In your leading article (21 January, p 131) a "conservative" dose of penicillamine in rheumatoid arthritis is stated to be 125$250 \mathrm{mg}$ increasing to $750 \mathrm{mg}$ daily. Many rheumatologists familiar with the drug find that a smaller maintenance dose such as $250-500 \mathrm{mg}$ daily is usually adequate, $750 \mathrm{mg}$ being only occasionally required. Still lower doses are being tried and results have been claimed with as little as $125 \mathrm{mg}$ penicillamine daily.

Though there appears to be a longer latent period before clinical effects are apparent with small doses, clearly there is a need to find the lowest effective dose of this drug as there is good evidence that the frequency and perhaps the degree of toxicity vary with the dose given.

Douglas Golding

Princess Alexandra Hospital, Harlow, Essex

\section{Interpretation of amylase clearance in patients with abnormal creatinine} clearance

SIR,-With reference to the short report by Dr R B Payne (7 January, p 22) we recently measured the amylase : creatinine clearance ratio (ACCR) of 36 patients admitted to hospital with acute abdominal pain. On calculating the ratio using the formula ACCR = (urinary amylase (Uam) : plasma amylase (Pam)/plasma creatinine (Pcr) : urinary creatinine (Ucr) $) \times 100$ we found that 25 patients with no evidence of pancreatitis had results in the normal range, seven patients with no evidence of pancreatitis had elevated ACCRs (false-positives), and three patients with acute pancreatitis had ACCRs in the normal range (false-negatives).

Recalculating the results using Dr Payne's formula-that is, ACCR $=$ (Uam : Pam $/(\mathrm{Ucr}$ : $\operatorname{Pcr}\left({ }^{0.799}\right) \times 100$-there was a reduction in the number of false-positive results to four and false-negatives to two.

Despite this improvement we would still agree with Durr et al that "grave doubts" 